\title{
Correction to: Eight-Year Experience of the Certifcate of Competence and Advanced Studies Program Organized by the European School of Oncology
}

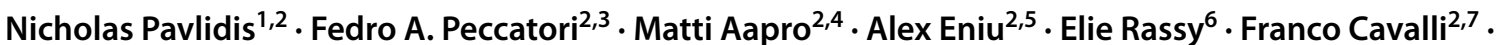 \\ Christian Rolfo ${ }^{8} \cdot$ Alberto Costa $^{2}$
}

Published online: 28 October 2021

(c) American Association for Cancer Education 2021

\section{Correction to: Journal of Cancer Education} https://doi.org/10.1007/s13187-021-02105-z

The original version of this article unfortunately contained a mistake. The name of the author Matti Aapro is now corrected in the author group.

The original article has been corrected.

Publisher's Note Springer Nature remains neutral with regard to jurisdictional claims in published maps and institutional affiliations.

The original article can be found online at https://doi.org/10.1007/ s13187-021-02105-z

Nicholas Pavlidis

npavlid@uoi.gr

1 University of Ioannina, Ioannina, Greece

2 European School of Oncology College (ESCO), Milan, Italy

3 Gynecologic Oncology Department, European Institute of Oncology IRCCS, Milan, Italy

4 Breast Center, Genolier Cancer Center, Genolier, Switzerland

5 Hospital Riviera Chablais, Rennaz, Switzerland

6 Département de Médecine Oncologique, Gustave Roussy, F-94805 Villejuif, France

7 Oncology Institute of Southern Switzerland, Belinzona, Switzerland

8 University of Maryland and Stewart Greenebaum Comprehensive Cancer Centre, Baltimore, USA 